\title{
Developing and Creating Board Game as a Media to Learn English Vocabulary for Senior High Student
}

\author{
Kevin Christopher, Bernardus Harnadi, Hendra Prasetya \\ Department of Information System, Faculty of Computer Science, \\ Soegijapranata Catholic University, Semarang, Indonesia \\ 14N10035@student.unika.ac.id, bharnadi@unika.ac.id,hendra@unika.ac.id
}

\begin{abstract}
Students have a general problem to even start learning the English language. Through the game, student will only feel that they're playing games and not studying, increasing the willingness of someone to learn more by averting their mindset to think that they are playing instead of studying.

The game will be created in a form of a board game, the reason is the game is seen as more a friendly and more acceptable by more people. The objective of this research is to design a board game helping student to increase their English proficiency in a friendlier, easier, and enjoyable manner

The board game was tested to 40 students on high school by letting them play it 10 times in different day each time they play, and then filling the questionnaire. The questionnaire then will be processed in SPSS software to conclude the result of the research.

This research will produce an English learning educational board game which will improve their English proficiency in a fun and cooperative way (togetherness).
\end{abstract}

Keyword - Board Game, English learning educational, Senior High Student

\section{INTRODUCTION}

According to Britanica Dictionary, the English language is a language that appeared around the middle age at England, and now become the most used language by the United State of America, United Kingdom, Canada, Australia, Ireland, New Zealand, and islands in the Caribbean Sea and Pacific ocean [1]. English language is the primary language that a lot of nation has chosen as their first foreign language to be learned, and thus solidified the
English language as the Global Lingua Franca, where now there's an estimation of $1 / 3$ population in the world has used the English language.

The English language has become an international language, where it has functioned as a social link for a lot of peoples from many different cultures, and languages. By understanding, and mastering this international language, someone will have a significant chance to open up his potential in his life. This significant increase of chance is backed up by the possibilities of someone to meet and communicate with other cultures, and thus help that person to broaden his/her knowledge.

In order for someone to increase his/her English language capability, he/she has to study and learn some basic aspects of English language such as Reading, Listening, Vocabulary, Grammar, and Writing. Between those 5 aspects, Vocabulary is the hardest one to learn and master. Vocabulary is the hardest one because of it's an absurd amount of words that someone needs to understand and memorize. To top it all, understanding the effective way to use the word, also required in order for someone to fully mastered the vocabulary aspect.

The statement above also backed by the result of the interview with 2 high school English teacher from 2 different schools (Sedes Sapiente High School, and Sint Louise High School). The result of the interview gives some additional information that: most of the High School student thought that 
Vocabulary is the most daunting aspect of learning the English language, followed closely by Speaking, and Listening.

The English language has been proven (from Interview) posses a lot of challenges for students to even start. In order to make students not feeling overwhelmed, they need to learn it the fun way, and by voluntarily. By using the traditional method like "do this homework" or "read a book from this chapter to that chapter" only make the students more reluctant to even start. In addition, usually, that kind of method tend to be pushed over to the student, instead of voluntarily taken by the student, and thus by making it looks like a burden more than anything else, and in the end just made them, even more, hate it.

According to a "Antecedents of the Adoption of Online Games Technologies", and "An investigation of the adoption of online game technologies in Indonesia" the most relevant Variables that can be used in the research are: Flow Experience, perceive Enjoyment, Performance Expectancy, Effort Expectancy, and Behavioral Intention.[2][3] In addition, the $6^{\text {th }}$ variable (Togetherness) was added in order to answering some of the research question that previously cannot be answered.

In this regard, a conclusion can be taken, that in order to make the student not feeling overwhelmed, and gain a more effective way to learn the English language, we need to make a method where it's fun, and it can make the student do it voluntarily, without being ordered to do so. One of the methods that we can use is using a game as a media for them to learn it. The game can be an effective way to do it, because: playing the game is an activity to pleased someone's heart [4]. By using an exciting, and fun game as a camouflage for learning the English language, students will be more eager to try it. Using game also answered the second problem, where students need to do it voluntarily and don't need to be ordered to do so. Because game basically is an activity that most teenager love to do, it should make them wanted to do it without being told to do so [5]. By switching student's obligatory act to learn into a voluntary act, the student is expected to have fun when learning and can do it for an extended period of time.

Unfortunately, using the digital game will not be the best way to do it. it's not the best way because digital games have that stereotype of "being a bad influence for kids an teenager", and thus makes parents, and teacher very reluctant to let their child play that kind of game. That's why other types of game are required to bypass this kind of stereotype/stigma, and the better type of game that suits for the task is a board game.

Board game is known for their trademark of being a healthy game, and usually help it's player to develop more understanding of something, or even increasing the logical skill of the player (example: Monopoly, Chess), beside that board game also makes the player communicate with each other, increasing their bonding, and communication skills. This is why in some country, board game become a tradition where a family will spend their quality time together by playing a board game, hence creating the term "Board game night". In addition, the board game has come around for a very long time, and most likely known by grown up or parents, thus making it easier for them to let their children play it.

In the end, by using the game as a media we try to shift student's mindset from thinking they are studying, into thinking that they are playing, subsequently giving them the incentive to learn by their own will in order to finish the game.

\section{Research Questions}

Based on the background research, there areas few problems that could be addressed:

1. How to create a board game that can increase a student's English vocabulary?

2. How to create a board game that is interesting and has a high replay ability aspect 
3. How to create a board game that make the player intend to play it again and again

\section{Research Objective}

Based on the Background Research, and the Formulation of the Problem, the objective of this research are:

1. Discover a game design that increased student's English vocabulary.

2. Develop, and create a board game that is interesting, and has a high replay ability aspect

3. Develop, and create a board game that make the player intend to play it again, and again

\section{METHOD}

\section{The object of Data Collection}

In this research, the type of interview that used is an unstructured interview, where the object of the interview is the English teacher of Sedes Sapiente High School, and Sint Louise High School.

Another type of data gathering that used is survey method that targeted around 40 peoples, in which this case is the high scholar in Sedes Sapiente.

\section{The Technique of Data Collection}

During research, the data sources are divided into 2 different types; Primary Data, and Secondary Data. The Primary Data is obtained via a direct interview where the interview's type is the unstructured interview, and questionnaire, where the questionnaire's type is quota sampling.

The Secondary Data is obtained via online podcast video, E-Book, online Classes, online website, etc.
Series of Research Method:

1. Information gathering related to creating an educational board game.

2. Designing, and developing an educational board game.

3. Play testing the board game.

4. Testing Intention to use board game

5. Analyzing and data processing.

\section{Development Method}

During the development of educational board game, the software that we used is Adobe Photoshop. It's used for designing and editing pictures.

These are the steps, and preparation that are taken for creating the educational board game can be seen in flowchart below:

1. Gathering data about design, and learning the subject for the board game.

2. Designing the appearances, and Mechanism of the board game.

3. Further development of the board game. This including creating all the component that will be needed, and used in the playtest session.

4. Do a playtesting session with the respondent, and spread survey to the subject

5. Analyze the Statistic Result, based from the collected survey that has been given to the participant

6. Determined if the board game fulfil all the standard requirement based on the statistic result. 


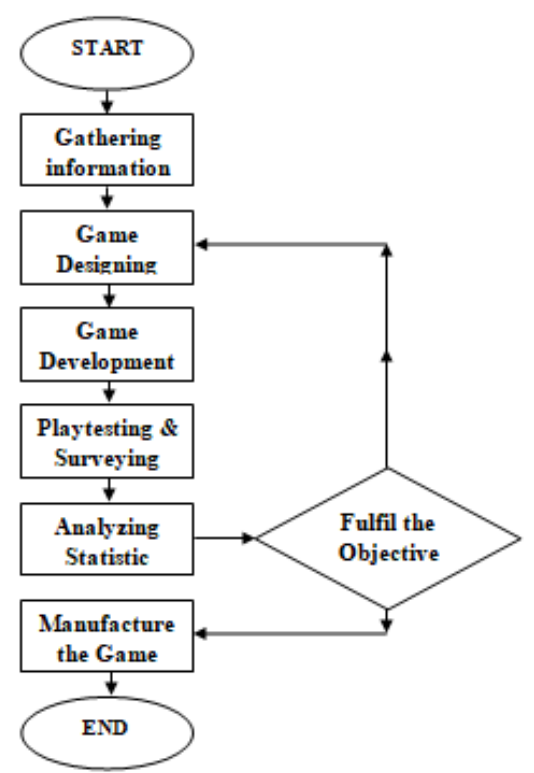

Figure 1 Development Flowchart

\section{GAME DESIGN}

In the Mystic Runner Board game, there are components that are core to the game mechanic, those components are:

1. Event card serves as a randomizer in the whole game process, the randomizer function as a method to keep the player have to think a new strategies, since the event card that revealed may benefit, or disturb the player's strategies.

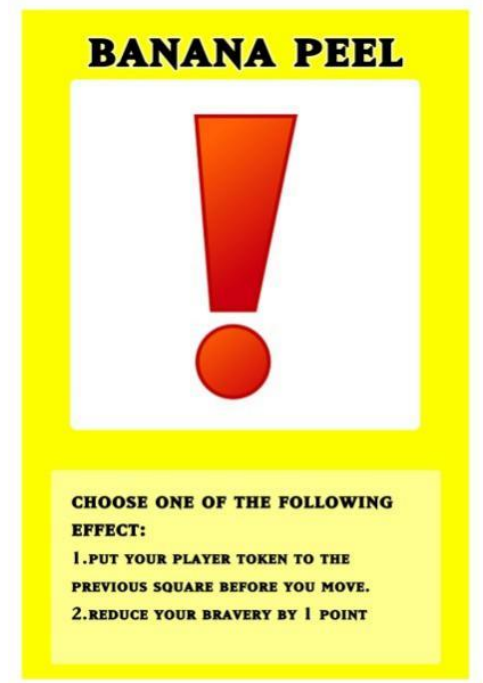

\section{Figure 2 Event Card}

2. Ghost card is one of the enemy that a player will face during the game. The ghost will present the player with an English question, in this regard, an Idiom related question.

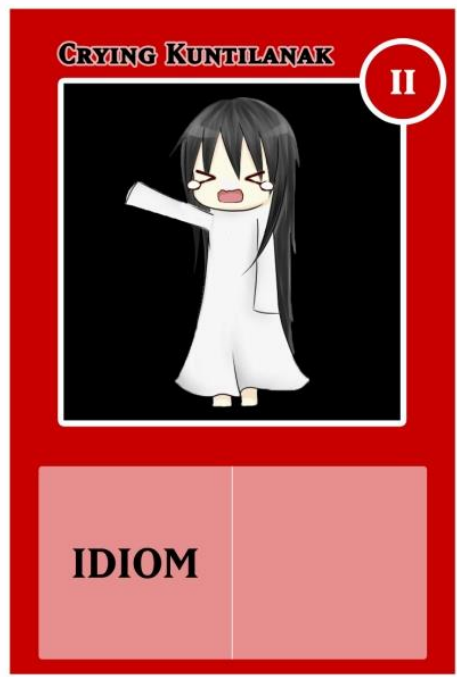

Figure 3 Ghost Card

3. Magical Index Card will function as the question that other player will give to the player, who are encountered a ghost card. This card will provide the Idiom, the meaning, and an example of the usage of that idiom.

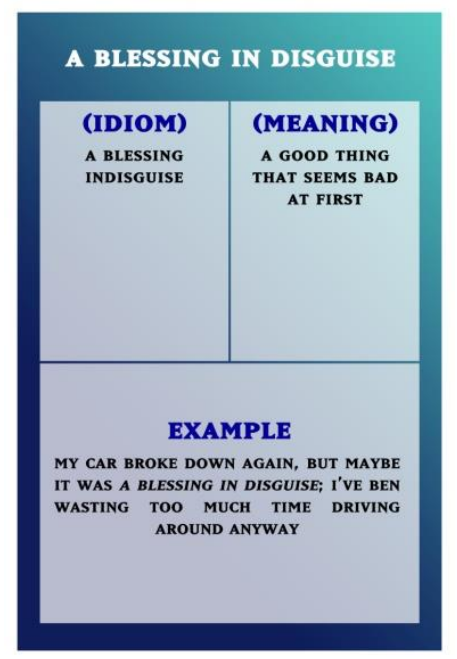

Figure 4 Magical Index Card

4. Before the game begin, players must setup the board based on the instruction that written in the game manual. The setup will be including placing the building, Sacred/Fake Orb, player token, sanity token, idiom Pile, and Event Pile 


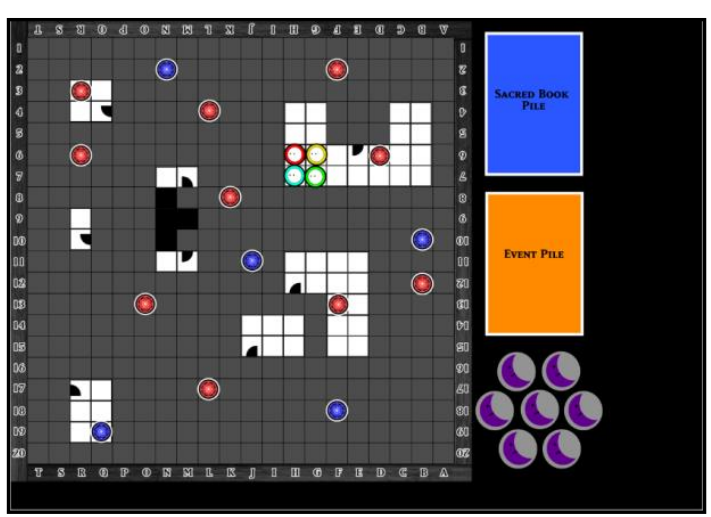

Figure 5 Board Set up

\section{GAME EVALIATION}

Model and Hypothesis Development

\section{H1 Performance Expectancy}

(PE):Performance expectancy will influence

Intention to play Mystic Runner Board Game.

H2 Perceive Enjoyment (EJ): Enjoyment will influence Intention to play Mystic Runner Board Game

H3 Flow Experience (FE):Flow Experience will influence Intention to play Mystic Runner Board Game

H4 Togetherness (TG):Togetherness will influence Intention to play Mystic Runner Board Game

\section{H5 Effort Expectancy (EE): Effort} Expectancy will influence Intention to play Mystic Runner Board Game

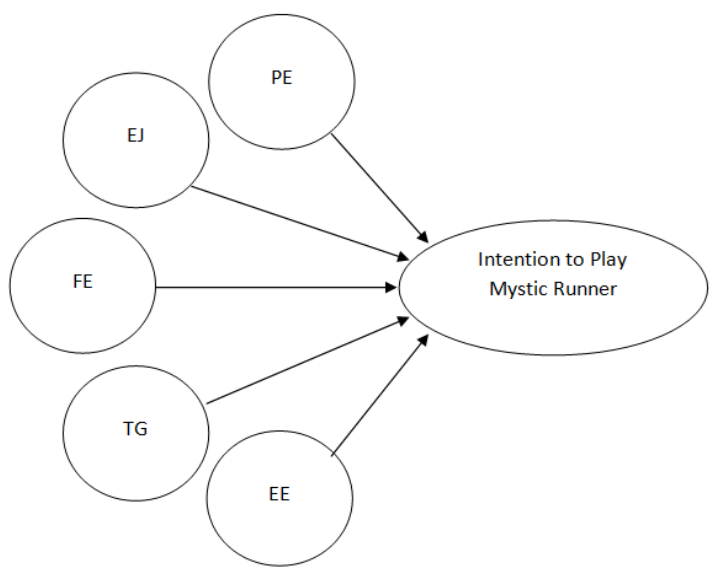

Figure 6 Hypothesis Model

\section{Description Analysis}

The process of gathering all of the data used in this statistic analysis was done in 1 week by play testing, then surveying the subject. The subjects are 40 high school students from Sedes Sapiente High School, located in Semarang City. The details can be seen in the Descriptive Analysis table below.

Table 1 Description Analysis Table

\begin{tabular}{|l|l|l|l|}
\hline & \multicolumn{3}{|c|}{ Gender } \\
\hline & Male & Female \\
\hline Frequencies & 37 & 3 \\
\hline Percentage & $92.5 \%$ & $7.5 \%$ \\
\hline & \multicolumn{3}{|c|}{ Age } \\
\hline & 17 Years & 18 Years & 19 Years \\
\hline $\begin{array}{l}\text { Frequenc } \\
\text { ies }\end{array}$ & 5 & 7 & 28 \\
\hline $\begin{array}{l}\text { Percentag } \\
\text { e }\end{array}$ & $12.5 \%$ & $17.5 \%$ & $70 \%$ \\
\hline & \multicolumn{3}{|c|}{ Experience (Months) } \\
\hline & $\mathbf{1 - 4}$ & $\mathbf{5 - 1 0}$ & $>10$ \\
\hline $\begin{array}{l}\text { Frequenc } \\
\text { ies }\end{array}$ & 8 & 24 & 8 \\
\hline $\begin{array}{l}\text { Percentag } \\
\text { e }\end{array}$ & $20 \%$ & $60 \%$ & $20 \%$ \\
\hline
\end{tabular}

\section{Validity Test}

\section{R table}

In this part the validity testing will help to determine which part of the survey that are valid for further statistic evaluation. In this case, the survey have 6 hypothesis that are need to be tested by implementing 3 similar question for each hypothesis.

\section{Factor Analysis}

To ensure the validity of the result, a Factor Analysis is required in double checking the result of the R table Validity Test. By input all of the variable into the SPSS we can check which variable did not match the requirement of being valid. The result can be seen in the factor analysis table below.

Table 2 Factor Analysis Table

\begin{tabular}{|l|r|r|l|}
\hline & $\mathbf{1}$ & \multicolumn{1}{c|}{$\mathbf{2}$} & $\mathbf{3}$ \\
\hline EJ1 & $\mathbf{. 8 8 7}$ & -.088 & .088 \\
\hline EJ2 & $\mathbf{. 8 9 6}$ & -.014 & .010 \\
\hline EJ3 & $\mathbf{. 7 9 3}$ & .016 & .314 \\
\hline
\end{tabular}




\begin{tabular}{|l|r|r|r|}
\hline TG2 & $\mathbf{. 8 7 2}$ & .011 & .337 \\
\hline TG3 & $\mathbf{. 4 7 7}$ & .252 & .279 \\
\hline EE1 & .195 & -.087 & $\mathbf{. 8 9 2}$ \\
\hline EE2 & .061 & -.017 & $\mathbf{. 8 2 0}$ \\
\hline EE3 & .097 & -.109 & $\mathbf{. 8 2 0}$ \\
\hline IT1 & $\mathbf{. 9 5 8}$ & -.033 & .106 \\
\hline IT2 & $\mathbf{. 9 6 5}$ & -.074 & .141 \\
\hline IT3 & $\mathbf{. 9 4 2}$ & .059 & .202 \\
\hline
\end{tabular}

Based on the reliability table, we can determine every variable that already been tested, and the result are shown in the Cronbach's alpha result table below.

Table 3 Cronbach's Alpha Result Table

\begin{tabular}{|c|c|c|}
\hline Variables & $\begin{array}{c}\text { Cronbach } \\
\text { Alpha }\end{array}$ & $\begin{array}{c}\text { Internal } \\
\text { Consistency }\end{array}$ \\
\hline EJ & .879 & Good \\
\hline TG & .683 & Questionable \\
\hline EE & .825 & Good \\
\hline IT & .977 & Excellent \\
\hline
\end{tabular}

As seen on the above table, the variable shown a various internal consistency. IT, and FE has an Excellent score, where EE, and EJ has a Good score, while TG has a questionable score.

\section{Correlation Evaluation}

In the correlation test all of the demographic data, and mean variable (SEJ, SFE, STG, SEE, SIT) are calculated to find the correlation between the variables. will be tested for it's reliability usi Cronbach Alpha Coefficient.

Table 4 Correlation Table

\begin{tabular}{|c|c|c|c|c|c|c|c|c|c|}
\hline & Age & Gender & Duration & Last_Time & SEJ & SFE & STG & SEE & SIT \\
\hline Age & 1 & $-.391^{*}$ & .020 & .178 & .125 & $.349^{*}$ & .096 & -.016 & .102 \\
\hline Gender & $\begin{array}{r}- \\
.391^{*}\end{array}$ & 1 & .190 & .026 & .155 & -.072 & .058 & -.210 & .106 \\
\hline Duration & .020 & .190 & 1 & $.466^{* *}$ & $.699^{* *}$ & -.029 & $.713^{* *}$ & $.500^{* *}$ & $.750^{* * *}$ \\
\hline Last_Time & .178 & .026 & $.466^{* *}$ & 1 & $.554^{* *}$ & $.440^{* *}$ & $.644^{* *}$ & .232 & $.545^{* *}$ \\
\hline SEJ & .125 & .155 & $.699^{* *}$ & $.554^{* *}$ & 1 & -.044 & $.773^{* *}$ & .297 & $.941^{* * *}$ \\
\hline SFE & $.349^{*}$ & -.072 & -.029 & $.440^{* *}$ & -.044 & 1 & -.003 & -.150 & -.042 \\
\hline STG & .096 & .058 & $.713^{* *}$ & $.644^{* *}$ & $.773^{* *}$ & -.003 & 1 & $.361^{*}$ & $.841^{* * *}$ \\
\hline SEE & $\begin{array}{r}- \\
.016\end{array}$ & -.210 & $.500^{* *}$ & .232 & .297 & -.150 & $.361^{*}$ & 1 & .285 \\
\hline SIT & .102 & .106 & $.750^{* *}$ & $.545^{* *}$ & $.941^{\text {** }}$ & -.042 & $.841^{\text {** }}$ & .285 & 1 \\
\hline
\end{tabular}

Based on the result in the Correlation table above it was determined that people with higher experience of playing board game, valued a board game more to their enjoyment, and togetherness factor.

\section{CONCLUSION}

After a series of research, play testing, and surveying, the answer of the research question that were asked in the beginning can finally be answered. The first question of the research 
question is "How to create a board game that can increase a student's English vocabulary?" based on the research, peoples are more interested in a game which support togetherness, and has a enjoyable game mechanic. Based on that information, in order to make a person increase their vocabulary via board game, an English language oriented board game must endorse the cooperation factor more, and carefully craft it's mechanic in order to give it's player as many enjoyable time as possible, thus subsequently increasing its player's duration of playing it, making it's learning process more effective, and intense.

The second question "How to create a board game that is interesting and has a high replay ability aspect?" the answer to this research question is almost identical with the first one, but the only difference is the way to approach it. based on the research, in order to make a board game interesting in the eye of the player (in this case student), an enjoyable game mechanic must be designed and implemented to the game. It doesn't have to be very easy or painstakingly hard since player only need it to be enjoyable in their perspective. Beside an enjoyable game mechanic, the game must also provide some sort of cooperation or interaction with other player which lead them to have some sort of togetherness while playing the game.

The third question "How to create a board game that make the player intend to play it again and again?" also boils down to the same answer as the previous question. A board game need to be fun to play with, and have a decent aspect of togetherness in order to make it's player willing to play it again. An in addition, by applying the theory of Skimmer Box we can further boost the willingness by unconsciously pushing player's psychological mindset to certain condition that will make them willingly to play again, and again.

\section{Recommendation}

This research is still far from perfect, and has a lot of flaws in it. during the whole span of this research, there're some mistake, and drawbacks that are hampering the research process. This research could be done better by fixing some issues such as :

\section{Increasing the number of participant for test subject, and surveys.}

During this research i find out that the 40 test subject that are subjected to the test is not sufficient to give us the accurate data. The 40 test subject still give somewhat an accurate result, but it can be more precise, and reliant if the amount of subject participant is increased.

\section{Make a better, and easier to understand survey question.}

Based on the survey result, some of the respondent seems to fails to identify the meaning of the survey's question. Making their answer is not convergent with the other answer that are prepared in the same category. If the questions that are asked are more easy to be understand and not overly convoluted a more desirable respond can be obtained.

I hope in the next Research, these issues could be fixed, and hopefully produced an even better, and accurate result than what have been done. Conclusion provides a statement expected as stated in the "Introduction" chapter and have been discussed in "Results and Discussion" chapter, so there have compatibility. Moreover, it can also be added the prospect of the development of results and prospects of further studies into the next (based on result and discussion).

\section{REFERENCES}

[1] Crystal, D., \& Potter, S. (2018, October 19). English language. Retrieved September 4, 2018, from https://www.britannica.com/topic/Engli sh-language

[2] B. Harnadi, "Antecedents of the Adoption of Online Games Technologies: The Study of Adolescent Behavior in Playing Online Games" 
International Journal of Gaming and Computer-Mediated Simulations, 2016 2nd International Conference on Science in Information Technology (ICSITech)

[3] B. Harnadi, "An investigation of the adoption of online game technologies in Indonesia," International Journal of Gaming and Computer-Mediated Simulations, vol.8, no. 4, article 2, 2016.

[4] Setiawan, E. (n.d.). Kamus Besar Bahasa Indonesia (KBBI). Retrieved September 4, 2018, from https://kbbi.web.id/main

[5] Credits, E. (2013, August 22). Retrieved September 4, 2018 